\title{
Circuler, vivre et habiter en Chartreuse
}

\section{Colette Annequin}

\section{Q OpenEdition \\ Journals}

Édition électronique

URL : http://journals.openedition.org/adlfi/7015

ISSN : 2114-0502

Éditeur

Ministère de la culture

\section{Référence électronique}

Colette Annequin, "Circuler, vivre et habiter en Chartreuse », ADLFI. Archéologie de la France -

Informations [En ligne], Rhône-Alpes, mis en ligne le 01 mars 2007, consulté le 19 avril 2019. URL

http://journals.openedition.org/adlfi/7015

Ce document a été généré automatiquement le 19 avril 2019

(c) Ministère de la Culture et de la Communication, CNRS 


\title{
Circuler, vivre et habiter en Chartreuse
}

\author{
Colette Annequin
}

Identifiant de l'opération archéologique : 229416

Date de l'opération : 2007 (PC)

1 La réunion de programmation scientifique interrégionale de novembre 2005 sur l'archéologie en Rhône-Alpes, présidée par Françoise Dumazy, avait mis en évidence la nécessité d'un travail collectif sur la montagne (BSR 2006, 2,:165-168). Dans cette perspective a été élaboré le cadre, très général, d'un projet de PCR «Circuler, vivre et habiter en Vercors et Chartreuse : la montagne et ses piémonts de la Préhistoire à la fin du Moyen Âge ».

2 L'équipe avait accepté le principe proposé par la CIRA, d'une année "probatoire» consacrée à la réalisation d'un état des lieux qui fonderait plus sûrement le choix des secteurs tests et des thèmes qu'il conviendrait d'étudier. Une réunion (MSH Alpes, Grenoble) a eu pour but d'organiser ce travail d'inventaire des sources et des données archéologiques existantes (CPI, Grenoble et AVDPA), d'élaborer une fiche d'inventaire utilisable par tous les chercheurs du groupe des préhistoriens aux médiévistes. Cette fiche comportait deux versions :

3 Au terme de cette année probatoire (en fait un semestre consacré en partie à l'élaboration de l'outil de travail), un inventaire a été engagé que l'équipe se proposait de poursuivre une année encore.

\section{Les données environnementales}

4 Il était essentiel d'avoir une idée aussi précise que possible de l'environnement pour mieux comprendre le peuplement des massifs concernés par l'inventaire. 
Pour connaître la végétation passée et son évolution, l'étude du pollen fossilisé dans les milieux humides constitue la méthode la plus performante, complétée ponctuellement par l'anthracologie et la carpologie.

Une liste des lieux humides (tourbières, marais ou lacs) ayant déjà fait l'objet d'études polliniques dans le passé ou présentant, a priori, un potentiel pour de futures analyses a été établie. Les sites retenus sont les milieux naturels les plus proches des massifs du Vercors et de Chartreuse. L'analyse des sites archéologiques (ex: Choranche, SaintThibaud-de-Couz, Grande Rivoire) apporte également des informations précieuses mais plus directement dépendantes des activités anthropiques; elle n'a pas été prise en compte. Cette liste peut paraître longue, mais en fait nombre de ces analyses sont inutilisables pour différentes raisons :

- analyses anciennes ne prenant pas en compte tous les taxons et réalisées suivant un pas d'échantillonnage élevé (plusieurs dizaines de centimètres) interdisant la connaissance fine que nous recherchons de l'évolution des paysages (ex : analyses de J. Becker, 1952);

- période concernée par l'analyse limitée au Tardiglaciaire et tout début de l'Holocène (cas de La Thuile, Moras, Chevelu);

- éloignement du territoire concerné par l'inventaire (ex: sites de la Drôme tels Suze et confluent Drôme-Rhône).

7 À noter qu'il n'existe pas d'analyses dans les piémonts situés à l'est de la Chartreuse ou du Vercors. Celles qui existent concernent des sites d'altitude appartenant aux massifs alpins internes (David, 1993).

8 En conclusion, une étude pollinique réalisée suivant un pas d'échantillonnage le plus fin possible de sites nouveaux, tels celui du Peuil et de l'Alpette situés respectivement en Vercors et en Chartreuse, paraît susceptible d'enrichir nos connaissances encore très incomplètes sur l'évolution récente de la végétation de ces massifs.

\section{Inventaire par sites et par périodes}

Chaque site (ou indice de site) a donné lieu à l'établissement d'une fiche :

- la Préhistoire est la période la mieux documentée : Vercors (309), Chartreuse (56);

- âge du Bronze, âge du Fer : 146 fiches représentent l'ensemble des sites et sont à compléter ;

- période romaine : pour le Vercors, le Voironnais, la vallée de l'Isère : 313 fiches (La Drôme n'est pas entièrement traitée) ;

- pour la Chartreuse : 70 fiches (il manque une partie de la Savoie) ;

- Moyen Âge : un inventaire des établissements monastiques en Vercors et Chartreuse a pris pour point de départ les travaux réalisés entre 1992 et 2002 par l'équipe de JeanFrançois Reynaud sur les prieurés ruraux; toutes les données de ce nouvel inventaire sont loin d'être enregistrées (fin novembre : I76 fiches).

Pour compléter cette approche des études préalables ont été réalisées :

- pour un inventaire partiel des lieux habités (43 sites pour les communes d'Entremont-leVieux et de Saint-Pierre-d'Entremont) ;

- pour une étude de la circulation (repérage des voies et des chemins) ;

- pour apprécier, à l'échelle du mandement, les ressources (péages), l'occupation des terroirs (et par là même l'utilisation des plages altitudinales), la gestion de l'eau (artifices de la vallée du Guiers Mort). 
11 Fin 2007, 1047 fiches avaient ainsi été enregistrées (listing communiqué au SRA) mais l'inventaire n'était pas terminé: des fiches manquaient encore, certaines fiches enregistrées étaient loin d'être complètes, un important travail de vérification et de relecture restait nécessaire pour éliminer d'éventuels doublons, rationaliser certaines entrées, homogénéiser les données, compléter, corriger peut-être. Subsistait enfin à croiser nos données avec celles de la CPI (opération engagée le 2 juillet mais qui ne sera effective que lorsque notre base de données sera complète).

\section{Perspectives}

Sur la base de cet inventaire encore inachevé, les perspectives sont prometteuses pour étudier à long terme, quelques accès à la Chartreuse (1) et au Vercors (2 voire 3, étaient envisagés) à partir des axes de grande circulation que sont la vallée de l'Isère et celle de la Drôme d'une part, la vallée du Drac d'autre part. Conditions géomorphologiques et environnementales, parcours, raisons de cette montée en altitude en formeraient la trame. La comparaison pourrait alors porter aussi bien sur les secteurs tests que sur les grandes périodes chronoculturelles. La cartographie (inaboutie tant que l'inventaire n'est pas terminé) laisse pressentir des stratégies fort différentes dans l'utilisation de l'espace montagnard. Il reste que toute conclusion est à l'évidence prématurée et toute interprétation abusive alors que l'inventaire demeure inachevé.

\section{INDEX}

operation Projet collectif de recherche (PCR)

Index géographique : Rhône-Alpes, Isère (38), Savoie (73), Choranche, Saint-Pierre-d'Entremont, Saint-Thibaud-de-Couz, Entremont-le-Vieux

Index chronologique : Antiquité romaine, Moyen Âge, âge du Bronze, Préhistoire, âge du Fer

\section{AUTEURS}

COLETTE ANNEQUIN

SUP 